\title{
INFLUÊNCIA DE CENTRÍFUGA NO PROCESSAMENTO DO MEL DE ABELHA ${ }^{1}$
}

\section{CLEBER C. DA COSTA ${ }^{2}$, ROBERTO G. PEREIRA ${ }^{3}$, DARIO DE A. PRATA FILHO ${ }^{4}$}

RESUMO: Neste trabalho, estudou-se a influência do tipo de centrífuga utilizado no processamento do mel de abelha sobre os parâmetros reológicos, físico-químicos e sensoriais. Para a análise sensorial, trabalhou-se com 58 provadores que constataram mudanças no sabor das amostras. $\mathrm{Na}$ análise reológica, foi utilizado um reômetro RS50 conectado a um banho termostático K20-DC5, ambos da HAAKE, com um sensor de geometria cone-placa. Ocorreram diferenças significativas nos valores da viscosidade entre as duas amostras obtidas por meio dos respectivos modelos de centrífugas. O valor da viscosidade do mel obtido da centrífuga radial foi, aproximadamente, o dobro do valor do mel processado na centrífuga facial. Nenhuma alteração foi observada nos níveis de hidroximetilfurfural e umidade de ambas as amostras. No caso do mel obtido da centrífuga radial, obteve-se umidade de $20,6 \%$, enquanto o mel processado na centrífuga facial apresentou umidade de $20,2 \%$. Na análise sensorial, cerca de $69 \%$ dos provadores manifestaram preferência pelo mel processado na centrífuga radial, que consideraram o sabor doce menos acentuado e mais viscoso.

PALAVRAS-CHAVE: reologia, análise físico-química, análise sensorial.

\section{THE INFLUENCE OF THE CENTRIFUGE ON HONEY PROCESSING}

\begin{abstract}
This work has the objective of studying the influence of the centrifuge type utilized on honey processing by the rheological, the physical-chemical and sensorial characterization. In the sensorial analysis, 58 consumers verified some alteration in the flavour of samples. In the rheological analysis, a RS50 rheometer connected with a K20-DC5 thermostatic bath, both produced by HAAKE, were used to perform the tests. The sensor used in this case was a cone plate sensor. It was observed significative differences at the viscosity value between the two samples processed at each centrifuge. The viscosity value of the honey processed at radial centrifuge was approximately the double of the viscosity value of the honey processed at facial centrifuge. None alteration in the hidroximetilfurfural level and moisture was observed. The honey processed in the radial centrifuge had $20.6 \%$ of moisture and the honey processed in the facial centrifuge had $20.2 \%$ of moisture. In the sensorial analysis, $69 \%$ of consumers preferred the honey processed in the radial centrifuge and they considered this honey less sweet and more viscous.
\end{abstract}

KEYWORDS: rheology, physical-chemical analysis, sensorial analysis.

\section{INTRODUÇÃO}

O mel, produto viscoso, alimentício e aromático, apreciado desde o tempo da Grécia antiga, é produzido pelas abelhas melíferas a partir do néctar das flores ou "honeydew" - secreções adocicadas produzidas por hemípteros, afídeos (pulgões) e cigarrinhas, que são insetos que se alimentam da seiva dos vegetais (BRASIL, 1997 e DUSTMANN, 1993).

As propriedades do mel são influenciadas por vários fatores, tais como a composição, a temperatura, além da quantidade e do tamanho dos cristais. A viscosidade é um parâmetro

\footnotetext{
${ }^{1}$ Extraído da dissertação de mestrado do primeiro autor.

${ }_{2}^{2}$ Mestre em Engenharia Mecânica, Departamento de Engenharia Mecânica, Escola de Engenharia, UFF, Niterói - RJ

${ }^{3}$ Prof. Doutor, Departamento de Engenharia Mecânica, Escola de Engenharia, UFF, Niterói - RJ, temrobe@ @m.uff.br

${ }^{4}$ Prof. M.Sc., Departamento de Engenharia Agrícola, Escola de Engenharia, UFF, Niterói - RJ

Recebido pelo Conselho Editorial em: 23-6-2004

Aprovado pelo Conselho Editorial em: 22-8-2005
} 
extremamente importante para caracterizar um determinado tipo de mel. Essa propriedade é particularmente crítica durante o armazenamento, manuseio e processamento (ASSIL et al., 1991 e LARA et al., 1976).

A umidade é um fator de grande influência na viscosidade e quanto maior a umidade, menos viscosa será a substância, nesse caso, o mel. A umidade de diferentes tipos de mel pode variar de $13 \%$ a 29\% (JUNZHENG \& CHANGYING, 1998). O conteúdo de água do mel determina a possibilidade de fermentação a uma dada temperatura. Para dificultar a sua oxidação, o conteúdo de água não deve ultrapassar 19\% (CRAINE, 1987).

A presença de hidroximetilfurfural (HMF) também está relacionada com a variação de temperatura no mel. $\mathrm{O}$ mel recém-extraído contém muito pouca quantidade de HMF, porém, se o mel é armazenado em temperaturas elevadas ou se for aquecido a diferentes temperaturas (superiores a $40{ }^{\circ} \mathrm{C}$ ), os açúcares contidos no mel, especialmente a frutose, transformam-se em HMF por desidratação. A presença de HMF pode ser verificada no mel, por meio de sua reação em meio ácido (BLANCHI, 1990), indicando se o mel alguma vez sofreu a elevação da temperatura acima de $40{ }^{\circ} \mathrm{C}$, comprometendo suas propriedades químicas.

Antes da invenção das centrífugas, eram utilizadas prensas para a separação do mel dos favos, com o grande inconveniente de se inutilizarem os favos. Hoje, a maioria dos apicultores utiliza a centrífuga radial, na qual os favos ficam dispostos no raio do círculo de rotação, ou a centrífuga facial, na qual os favos se apresentam em posição tangencial ao plano cilíndrico (COUTO \& COUTO, 1996). A diferença básica que motiva a investigação do produto final é o fato de que, quando em rotação, na centrífuga radial, o mel escoa ao longo do quadro até entrar em contato com a parede da centrífuga. $\mathrm{Na}$ centrífuga facial, a posição do quadro que contém o favo de mel, faz com que exista um afastamento entre o quadro e a parede; dessa forma, quando iniciada a centrifugação, o mel é lançado diretamente contra a parede da centrífuga. Devido à diferença no processo de extração do mel, no presente trabalho, pretendeu-se investigar as variações que podem ocorrer no produto obtido nas diferentes centrífugas.

O objetivo deste trabalho foi estudar a influência do tipo de centrífuga utilizado na extração de mel de florada silvestre, sobre suas características reológicas, físico-químicas e sensoriais.

\section{MATERIAL E MÉTODOS}

\section{Origem das amostras}

As amostras foram coletadas de mel de mesma florada silvestre, de mesma colméia, localizada em Muqui - ES, colhido na mesma época do ano.

\section{Preparo das Amostras}

\section{Centrifugação das amostras}

Foram utilizados os modelos de centrífuga facial e radial para o processamento do mel. As centrífugas tinham raio de $0,45 \mathrm{~m}$, estando os quadros de alvéolos localizados juntos à parede do extrator. Inicialmente, foi imposta uma rotação baixa, para que os favos não se rompessem com o peso. Em seguida, a rotação foi aumentada lentamente até atingir cerca de 300 rotações por minuto, permanecendo nessa rotação até todo o mel ser expelido dos alvéolos (COUTO \& COUTO, 1996). As amostras coletadas foram armazenadas em potes de vidro higienizados e, posteriormente, filtradas.

\section{Filtragem das amostras}

Após serem centrifugadas, as amostras foram cuidadosamente filtradas, em malhas de $1 \mathrm{x} 1 \mathrm{~mm}$, para que restos de favos ou pedaços das abelhas fossem retirados. A malha foi posicionada sobre a 
boca de um recipiente de vidro e o mel foi sendo lentamente derramado sobre a malha. Por ação da gravidade, o mel escorria, à temperatura ambiente $\left(25^{\circ} \mathrm{C}\right)$, para o interior do pote, ao passo que os detritos ficavam retidos na malha.

\section{Análise reológica}

\section{Equipamento}

As medidas reológicas foram realizadas em um reômetro rotativo HAAKE-RS50, conectado a um banho termostático K20-DC5. Foi utilizado um sensor de geometria cone-placa $\left(\mathrm{C} 60 / 2^{\circ}\right)$ para realizar medições que descrevessem o comportamento reológico do material em estudo. $\mathrm{O}$ cone tinha diâmetro de $59,996 \mathrm{~mm}$ e ângulo de $1,993^{\circ}$, com truncamento de $0,104 \mathrm{~mm}$. O diâmetro da placa foi de $100 \mathrm{~mm}$.

Para cada teste realizado no reômetro, foram necessários $2 \mathrm{~mL}$ da amostra. As amostras foram coletadas com o uso de seringa descartável, graduada em décimo de mililitros. Após ser cuidadosamente medida, a amostra foi posicionada sobre a placa do reômetro, e o aparelho foi acionado para a posição de medida. Iniciou-se então o teste, após a amostra ter atingido a temperatura desejada para o ensaio.

\section{Teste de cisalhamento}

No teste de cisalhamento, a amostra de fluido a $25{ }^{\circ} \mathrm{C}$ foi submetida a um conjunto de tensões, dentro do intervalo de 1 a $100 \mathrm{~Pa}$, utilizando o método de tensão controlada (Controlled Stress - CS). Para cada valor de tensão aplicada, obteve-se um valor de deformação correspondente. A razão entre a tensão $(\tau)$ e a taxa de deformação $(\dot{\gamma})$ representa o valor da viscosidade $(\eta)$ da amostra. Com isso, um gráfico de $\eta$ versus $\dot{\gamma}$ foi construído, no qual se pode analisar o comportamento da viscosidade da amostra dentro do intervalo de tensão preestabelecida.

\section{Teste de oscilação}

Nos testes de oscilação, foram utilizados os métodos de varredura de tensão e de varredura de freqüência. No primeiro método, as amostram foram submetidas a tensões $(\tau)$ dentro do intervalo de 1 a $100 \mathrm{~Pa}$, estando a amostra a $25^{\circ} \mathrm{C}$ e sujeita à freqüência constante de $1 \mathrm{~Hz}$. Nesse teste, obtiveram-se valores para o módulo complexo $\left(\mathrm{G}^{*}\right)$, que representa a resistência total da substância contra uma deformação (razão entre a amplitude de tensão e a amplitude de deformação) (MACOSKO, 1994).

A partir desses valores, um gráfico de $\mathrm{G}^{*}$ versus $\tau$ foi construído, sendo possível analisar se a amostra se encontrava dentro de seu limite de viscoelasticidade linear.

No segundo método, as amostram foram submetidas a freqüências (f) dentro de um intervalo de 0,015 a $61 \mathrm{~Hz}$, estando a amostra a $25^{\circ} \mathrm{C}$ e sujeita à tensão constante de $1 \mathrm{~Pa}$. Nesse teste, foram obtidos valores para o ângulo de fase $(\delta)$. Nesse tipo de teste, a tensão e a deformação são funções oscilatórias temporais. Essas funções podem estar em fase $\left(\delta=0^{\circ}\right)$, fora de fase $\left(\delta=90^{\circ}\right)$ ou em um ponto intermediário entre $0^{\circ}$ e $90^{\circ}$. No primeiro caso, tem-se uma deformação máxima para uma tensão máxima aplicada e isso caracteriza um fluido elástico. $\mathrm{O}$ segundo caso equivale a uma tensão máxima aplicada, obtendo-se uma deformação mínima, o que caracteriza um fluido puramente viscoso e, finalmente, no caso intermediário, tem-se um fluido viscoelástico. Com os valores obtidos, um gráfico de $\delta$ versus $\mathrm{f}$ foi construído e, dessa forma, foi possível observar o comportamento reológico da amostra dentro do intervalo de freqüência considerado.

\section{Análise físico-química}

\section{Determinação da umidade}

Foi determinada pelo método refratométrico em refratômetro de bancada M/PZD, ref. RL3, com escala de 0 a 85\%. Em seguida, foi consultada a Tabela de Chataway (Tabela 1) para a obtenção dos valores de umidade das amostras (LARA et al., 1976). 
TABELA 1. Tabela de Chataway.

\begin{tabular}{cccc}
\hline Índice de Refração a $20{ }^{\circ} \mathrm{C}$ & Umidade $(\%)$ & Índice de Refração a $20{ }^{\circ} \mathrm{C}$ & Umidade $(\%)$ \\
\hline 1,5030 & 13,4 & 1,4930 & 17,4 \\
1,5025 & 13,6 & 1,4925 & 17,6 \\
1,5020 & 13,8 & 1,4920 & 17,8 \\
1,5015 & 14,0 & 1,4915 & 18,0 \\
1,5010 & 14,2 & 1,4910 & 18,2 \\
1,5005 & 14,4 & 1,4905 & 18,4 \\
1,5000 & 14,6 & 1,4900 & 18,6 \\
1,4995 & 14,8 & 1,4895 & 18,8 \\
1,4990 & 15,0 & 1,4890 & 19,0 \\
1,4985 & 15,2 & 1,4885 & 19,2 \\
1,4980 & 15,4 & 1,4880 & 19,4 \\
1,4975 & 15,6 & 1,4876 & 19,6 \\
1,4970 & 15,8 & 1,4871 & 19,8 \\
1,4965 & 16,0 & 1,4866 & 20,0 \\
1,4960 & 16,2 & 1,4862 & 20,2 \\
1,4955 & 16,4 & 1,4858 & 20,4 \\
1,4950 & 16,6 & 1,4853 & 20,6 \\
1,4945 & 16,8 & 1,4849 & 20,8 \\
\hline
\end{tabular}

* Correção para temperatura diferente de $20^{\circ} \mathrm{C}$ : adicione ou subtraia 0,00023 ao/do valor encontrado na tabela para cada grau acima ou abaixo de $20^{\circ} \mathrm{C}$.

\section{Determinação do HMF}

Adicionaram-se $7 \mathrm{~mL}$ de éter etílico em $2 \mathrm{~g}$ de mel de modo que, ao homogeneizar essa mistura com um bastão de vidro, o HMF presente no mel deslocou-se para o éter. Essa mistura de éter e HMF foi, então, extraída para um tubo de ensaio. Adicionaram-se $2 \mathrm{~mL}$ de uma mistura de resorcina a $1 \%$ e $\mathrm{HCl}$ ao éter etílico contendo o HMF. Essa nova solução foi deixada em um local escuro por aproximadamente $10 \mathrm{~min}$. Decorrido o tempo de descanso da solução, surge uma coloração a qual é comparada a uma tabela de cores na qual se indica a proporção, em miligramas, de HMF para cada 1 $\mathrm{kg}$ de mel (BLANCHI, 1990).

\section{Análise sensorial}

Foi utilizado o teste pareado de preferência, conforme representado na Figura 1. Foram utilizados 58 provadores, entre os quais, alunos e funcionários da Universidade Federal Fluminense. As amostras foram servidas à temperatura ambiente, em quantidades em torno de $5 \mathrm{~mL}$, codificadas com números de três dígitos, sendo a ordem de apresentação aleatória. Os horários dos testes foram entre as 9 e $12 \mathrm{~h}$ e das 14 às 17 h. A partir dos dados obtidos, foram confeccionados histogramas de preferência e de freqüência de consumo. 
Nome

Data:

Estamos fazendo uma pesquisa sobre a preferência do consumidor para este produto.

Prove as duas amostras e indique a sua preferência:

Prefiro a amostra

Dê a razão de sua preferência:

Você achou alguma diferença entre as amostras ? não ( ) $\operatorname{sim}(\quad)$

Se sim, indique-a (s).

Qual a frequiência de consumo deste produto:

( ) todos os dias ( ) ocasionalmente ( ) nunca

FIGURA 1. Ficha utilizada para o teste de preferência dos méis.

\section{RESULTADOS E DISCUSSÃO}

\section{Testes reológicos}

\section{Teste de cisalhamento}

Na Figura 2, pode-se observar que ocorreu variação significativa na viscosidade do mel devido aos diferentes modos de centrifugação. Segundo os dados obtidos à temperatura de $25{ }^{\circ} \mathrm{C}$, a viscosidade do mel centrifugado na centrífuga radial é aproximadamente duas vezes maior do que o mesmo mel centrifugado na centrífuga facial. No caso aqui estudado, as duas amostras apresentaram viscosidade não dependente da taxa de deformação aplicada.

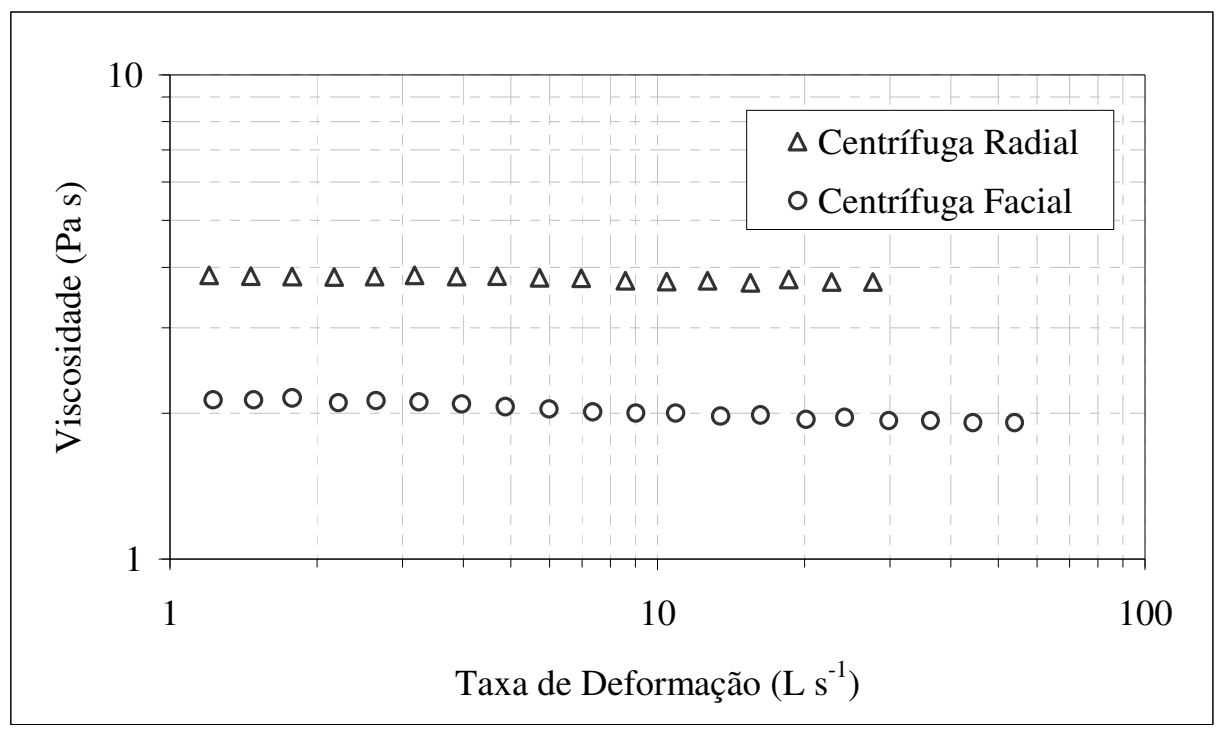

FIGURA 2. Curva de viscosidade obtida para temperatura de $25^{\circ} \mathrm{C}$.

Essa diferença apresentada entre a viscosidade das amostras pode estar relacionada com a mudança molecular do mel. O mel, além de apresentar em sua composição grande variedade de açúcares e proteínas, possui também vários álcoois e, dentre esses, alguns de baixo ponto de ebulição. Dessa forma, é possível que, no ato de o mel se chocar com a parede da centrífuga, no caso da centrífuga facial, o calor gerado pelo choque tenha sido suficiente para que alguns desses álcoois 
entrassem em ebulição, fazendo com que a cadeia molecular do mel fosse alterada. Novas pesquisas devem ser realizadas para o estudo dessa possível mudança molecular. Com isso, a viscosidade do mel após esse processo se altera. Desse modo, por meio da determinação da viscosidade, pode-se verificar, do ponto de vista reológico, a ocorrência de variações no mel, ou seja, sua forma natural foi alterada. Assim, à medida que, na centrífuga facial, o mel é lançado contra a parede, parece ocorrer mudança em sua estrutura, o que origina diminuição de sua viscosidade, comparativamente ao mel processado na centrífuga radial.

\section{Teste de oscilação}

Devido ao comportamento linear apresentado na Figura 3, ou seja, o módulo complexo $\left(\mathrm{G}^{*}\right)$ permanecendo constante para faixa de tensão aplicada, pode-se verificar que, para qualquer teste realizado nessa faixa, estando a freqüência em $1 \mathrm{~Hz}$ e a temperatura mantida constante em $25{ }^{\circ} \mathrm{C}$, a amostra da centrífuga facial e radial estão, ambas, dentro do seu limite de viscoelasticidade linear, ou seja, a estrutura do material não corre o risco de ser modificada.

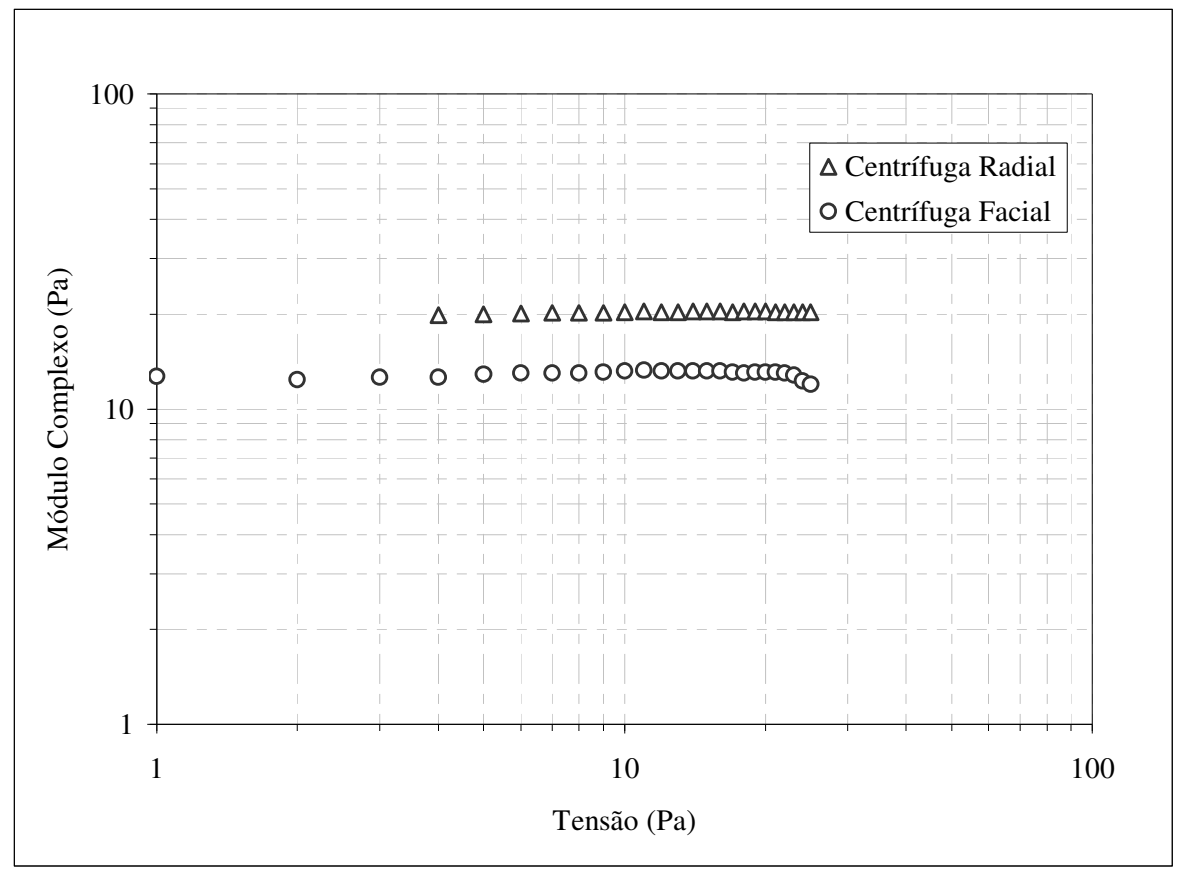

FIGURA 3. Varredura de tensão em que são mantidas constantes a frequiência $(1 \mathrm{~Hz})$ e a temperatura $\left(25{ }^{\circ} \mathrm{C}\right)$.

O comportamento viscoso do mel centrifugado em cada uma das centrífugas pode ser verificado na Figura 4. De acordo com os dados obtidos com o teste de varredura de frequiência, tanto o mel centrifugado na centrífuga radial quanto o centrifugado na facial apresentam comportamento puramente viscoso, evidenciado pelo ângulo de fase igual a $90^{\circ}$, dentro do intervalo de frequiência de $0,015 \mathrm{~Hz}$ a $1,47 \mathrm{~Hz}$. 


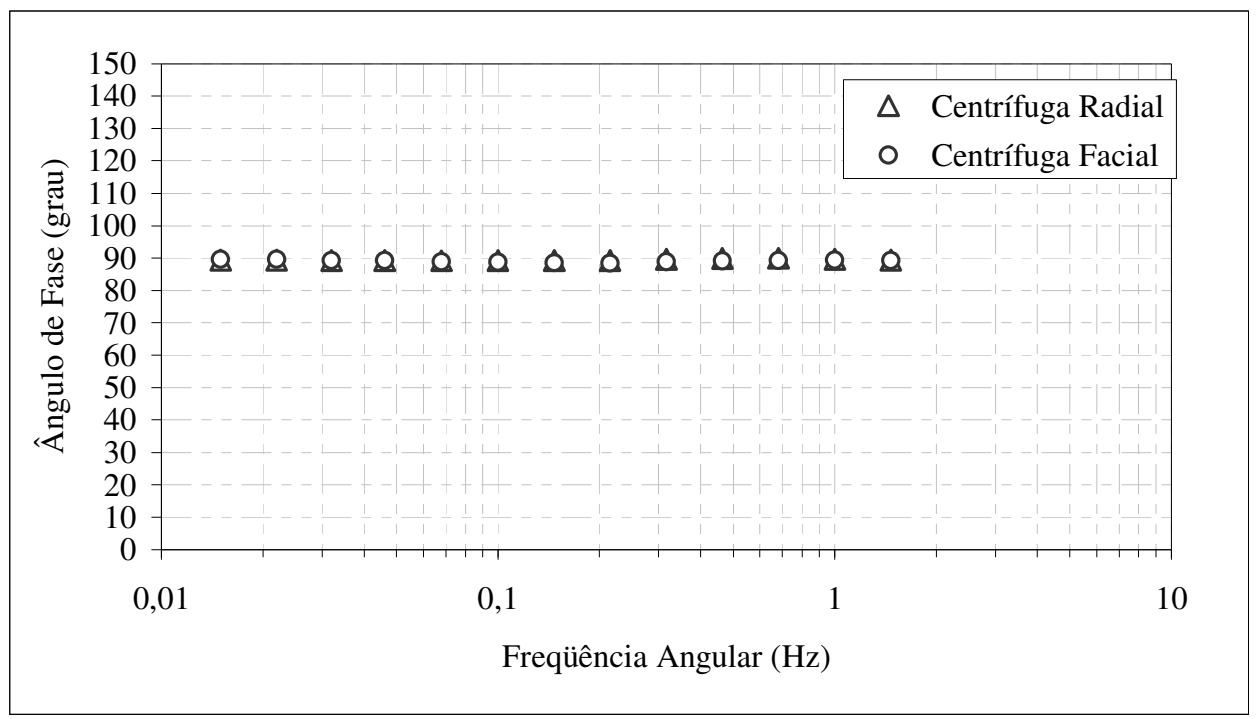

FIGURA 4. Varredura de freqüência em que são mantidas constantes a tensão (1 Pa) e a temperatura $\left(25{ }^{\circ} \mathrm{C}\right)$.

\section{Análises físico-químicas}

Nos testes físico-químicos de verificação da presença de HMF na amostra, constatou-se que as amostras centrifugadas na centrífuga radial e na facial encontram-se dentro do intervalo de 11 a $20 \mathrm{mg} \mathrm{kg}^{-1}$. Esse valor é inferior ao estabelecido pela legislação, cujo máximo é de $60 \mathrm{mg} \mathrm{kg}^{-1}$ (BRASIL, 2000), indicando que o mel não foi exposto a temperaturas elevadas, portanto, não tendo sido alterado o seu valor nutricional (BLANCHI, 1990).

O mel centrifugado na centrífuga radial apresentou umidade de $20,6 \%$, enquanto o mesmo mel centrifugado na facial indicou umidade de $20,2 \%$.

\section{Análise sensorial}

Verificou-se que $69 \%$ dos 58 provadores tiveram preferência pelo mel obtido pela centrífuga radial.

Dos 58 provadores que participaram da pesquisa, 54 deles $(93,1 \%)$ apontaram que as amostras eram diferentes, e 15 deles $(25,8 \%)$ descreveram que o mel obtido da centrífuga radial apresentou sabor doce, menos acentuado em relação à amostra obtida pela centrifuga facial.

Em relação à frequiência de consumo do mel de abelha, observou-se que $10 \%$ dos provadores consomem mel todos os dias, $81 \%$ dos provadores consomem ocasionalmente e $9 \%$ nunca consomem.

\section{CONCLUSÕES}

O valor da viscosidade variou significativamente, sendo obtido para o mel centrifugado na centrífuga radial, valor, aproximadamente, duas vezes superior ao da viscosidade do mesmo mel processado na centrífuga facial.

Não foram observadas variações em relação à umidade e à quantidade de HMF presente nas amostras.

Verificou-se que $69 \%$ dos 58 provadores preferiram o mel obtido pela centrífuga radial; 93,1\% apontaram que as amostras eram diferentes e $25,8 \%$ descreveram que o mel obtido da centrifuga radial apresentou sabor doce, menos acentuado, em relação à amostra obtida pela facial. 


\section{AGRADECIMENTOS}

Ao CNPq e à CAPES, pelo suporte financeiro prestado; ao Apiário Ervamel; à COAPI-Rio e ao Departamento de Nutrição e Dietética da UFF.

\section{REFERÊNCIAS}

ASSIL, H.I.; STRELING, R.; SPORNS, P. Crystal control in processed liquid honey. Journal of Food Science, Chicago, v.56, n.4, p.1034-41,1991.

BLANCHI, E.M. Control de calidad de la miel y la cera. Roma: FAO, 1990. 69 p.

BRASIL. Ministério da Agricultura e do Abastecimento. Regulamento da Inspeção Industrial e Sanitária de Produtos de Origem Animal. Decreto n⿳o 30.691 de 29 de março de 1952, alterado. Brasília, 1997.

BRASIL. Ministério da Agricultura, Pecuária e Abastecimento. Instrução Normativa 11, de 20 de outubro de 2000. Regulamento Técnico de Identidade e Qualidade do Mel, 2000.

COUTO, R.H.N.; COUTO, L.A. Apicultura: manejo e produtos. FUNEP: Jaboticabal, 1996. 156 p.

CRAINE, E. O livro do mel. 2.ed. São Paulo: Nobel, 1987. 226 p.

DUSTMANN, J.H. Honey, quality and its control. American Bee Journal, Hamilton, v.133, n.9, p.648$51,1993$.

JUNZHENG, P.; CHANGYING, J. General rheological model for natural honeys in China. Journal of Food Engineering, Essex, v.36, n.2, p.165-8, 1998.

LARA, A.B.W.H.; NAZÁRIO G.; ALMEIDA M.E.W.; PREGNOLATTO, W. Normas Analíticas do Instituto Adolfo Lutz: métodos químicos e físicos para análise de alimentos. 2.ed. São Paulo: Instituto Adolfo Lutz, 1976. v.1, 371 p.

MACOSKO, C.W. Rheology: principles, measurements and applications. USA: VCH Publishers, 1994. 118 p. 